\title{
Estratégias de Recuperação de Serviço no Varejo e seu Impacto na Fidelização dos Clientes
}

\author{
Kleber Fossati Figueiredo \\ Giovana Benevides Ozório \\ Rebecca Arkader
}

\section{Resumo}

Este trabalho apresenta resultados de pesquisa realizada junto a clientes do varejo brasileiro de bens, procurando identificar falhas percebidas no serviço, as estratégias de recuperação empregadas pelos varejistas e o impacto de tais estratégias sobre o comportamento futuro dos clientes no que se refere à repetição de compras. Utilizando-se a técnica do incidente crítico como metodologia exploratória, foram analisados 224 questionários válidos. Em 86 foram observadas estratégias de recuperação satisfatórias e, em 138, estratégias insatisfatórias. Foi possível identificar 13 tipos de falhas e 11 estratégias de recuperação. Os resultados sugerem que uma boa avaliação pelos clientes das estratégias de recuperação adotadas pelos varejistas influencia positivamente a retenção dos clientes.

Palavras-chaves: falhas em serviço; estratégias de recuperação; fidelização de clientes; erros no varejo.

\section{Abstract}

Difficulties in the prevential and recovery of failures in service operations have been credited to poor knowledge on their nature. Based on research with customers of goods retail operations in Brazil, the paper identifies perceived service failures, the recovery strategies employed by retailers to remedy them, and the impact of these strategies on resulting customer behavior. Using the critical incident technique, it was possible to identify 13 categories of failures and 11 recovery strategies used by operations. Results suggest that a good evaluation by customers of the recovery strategies adopted by retailers has a positive effect on customer retention.

Key words: service failures; recovery strategies; customer retention; retail failures. 


\section{INTRODUÇÃO}

Determinadas características dos serviços, como a simultaneidade entre produção e consumo e intensidade em mão-de-obra, fazem com que erros aconteçam, mesmo em sistemas bem gerenciados. Assim, um dos desafios mais importantes para os gerentes de operações de serviços é atuar no sentido de prevenir a ocorrência de erros e, quando estes aparecem, dispor de mecanismos que evitem a insatisfação dos clientes.

A recuperação de serviço, entendida como as atividades que uma empresa realiza para ouvir reclamações, resolver problemas e tentar mudar a atitude de clientes insatisfeitos, buscando mantê-los como clientes, está entre os temas mais abordados na literatura sobre serviços, tendo em vista o seu impacto sobre a participação de mercado (Hays e Hill, 1999), a satisfação dos clientes (Bateson, 1995; Sampson, 1999), a fidelização (Reichheld e Sasser, 1990; Lovelock, 1996) e a rentabilidade (Heskett, Sasser e Schlesinger, 1994; Reichheld, 1996).

Embora sejam conhecidos vários instrumentos visando à prevenção dos erros (QFD, ferramentas de controle estatístico de qualidade, poka-yokes), o progresso tem sido apenas limitado em virtude do desconhecimento quer da natureza, quer dos tipos de erros específicos de cada setor, o que impede uma atuação mais efetiva de prevenção ou mesmo de recuperação de falhas (Stewart e Chase, 1999).

Diversas pesquisas têm sido conduzidas em todo o mundo, procurando conhecer o comportamento do consumidor de serviços diante de situações de erros, durante a prestação de serviços, e como as empresas responsáveis pelos erros atuam quando o cliente apresenta uma reclamação. Os resultados de tais pesquisas demonstram que situações de insatisfação podem gerar forte propaganda negativa boca-a-boca. Esse problema pode ser evitado, quando a organização está preocupada em ouvir as reclamações dos clientes e resolver cada situação de forma a promover a satisfação absoluta e a credibilidade da empresa.

A preocupação com a recuperação dos serviços também é de suma importância, quando se considera o abalo no moral dos funcionários que ouvem reclamações e, em alguns casos, acabam sendo agredidos verbalmente por clientes insatisfeitos. A disponibilização de respostas efetivas às possíveis reclamações sinaliza a existência de uma política de encorajamento de ações corretivas e de busca da satisfação total dos clientes, trazendo vantagens para o negócio a longo prazo. 
O varejo de bens é um serviço caracteristicamente marcado pela simultaneidade produção-consumo e pelo uso intensivo de mão-de-obra, em que as falhas ocorrem com certa freqüência. Por sua natureza dinâmica e altamente competitiva, esse é um setor cuja essência está na construção de uma base de clientes fiéis, o que constitui tarefa cada vez mais difícil para os varejistas, devido ao amplo número de opções de compras que os clientes têm à disposição. Alguns autores defendem que a preservação da fidelidade dos clientes pode ser obtida por meio da busca da sua satisfação total, mediante a compreensão do que lhes é importante, do estabelecimento de padrões de qualidade e da implementação de uma estratégia de recuperação de falhas.

Este trabalho tem por objetivo apresentar os resultados de um estudo que procurou identificar falhas e problemas recorrentes na prestação do serviço no varejo de bens no mercado brasileiro, as diferentes estratégias de recuperação utilizadas pelos varejistas e o seu efeito na satisfação do cliente e seu comportamento posterior de compra, ou seja, a sua fidelidade com relação à empresa onde o problema foi vivenciado.

\section{Aspectos Conceituals}

Como foi definido por Grönroos (1995), o nível de qualidade percebido por um cliente com relação a um serviço é determinado pela diferença entre a qualidade esperada antes de receber o serviço e a qualidade experimentada durante e após a sua prestação. Quando o serviço prestado não atinge o nível de expectativas do cliente, há um problema de qualidade ou uma falha na prestação do serviço. Daí decorre que a compreensão da origem e da natureza das falhas é fundamental para a gestão da qualidade em empresas de serviço.

As falhas em serviços podem ser de naturezas diferentes, como demonstra o estudo conduzido por Bitner, Booms e Tetreault (1990), que, a partir de uma análise de falhas sob a perspectiva do cliente em três setores distintos de serviço (empresas aéreas, hotéis e restaurantes), propuseram a sua classificação em três grupos diferentes.

. O grupo 1 refere-se às falhas decorrentes de respostas dos funcionários a problemas no sistema de prestação de serviço. São as que acontecem quando a empresa não se prepara para prestar os serviços nos padrões de qualidade desejados pelos clientes. Exemplos desse procedimento podem ser serviços lentos ou serviços indisponíveis. Trata-se, portanto, de falhas no projeto do serviço. 
. O grupo 2 engloba as falhas originárias de respostas dos funcionários a necessidades e pedidos específicos de clientes. Essas falhas ocorrem quando os funcionários ou a empresa não são capazes de responder a uma necessidade ou a preferência particulares.

- O grupo 3 é constituído pelas falhas decorrentes de atitudes imprevisíveis e não desejadas do pessoal de contato. Elas surgem quando há uma falha de atenção ou comportamento fora do comum por parte de certo funcionário.

Kelley, Hoffman e Davis (1993) procuraram não só identificar as falhas no varejo de bens, mas também classificá-las e categorizá-las. A partir da análise de 661 incidentes críticos, propuseram uma tipologia de quinze falhas, que estruturaram subgrupos por sua vez enquadráveis nos grupos 1, 2 e 3 de Bitner, Booms e Treteault (1990). A tipologia de estratégias de recuperação resultante dessa análise é constituída por doze categorias de estratégias, cinco das quais avaliadas como inaceitáveis pelos clientes, com impactos negativos sobre a sua satisfação e a sua retenção. A tipologia mencionada é apresentada a seguir.

\begin{tabular}{lccc}
\hline O que a empresa fez para recuperar & $\begin{array}{c}\text { Número } \\
\text { de } \\
\text { vezes }\end{array}$ & $\begin{array}{c}\text { Avaliação } \\
\text { da } \\
\text { Recuperação* }\end{array}$ & $\begin{array}{c}\text { Pecentual } \\
\text { de } \\
\text { Retenção** }\end{array}$ \\
\hline Concessão de desconto & 22 & 8,86 & $86,4 \%$ \\
Correção da falha & 81 & 8,81 & $96,3 \%$ \\
Intervenção do Gerente/Outro empregado & 12 & 8,42 & $75,0 \%$ \\
Correção Plus (mais que a correção simples) & 21 & 8,24 & $90,5 \%$ \\
Troca de produtos (defeituosos ou não) & 173 & 7,91 & $87,8 \%$ \\
Pedido de desculpas & 53 & 6,75 & $77,4 \%$ \\
Reembolso & 81 & 6,48 & $81,5 \%$ \\
Necessidade de o Cliente iniciar a correção & 6 & 3,83 & $50,0 \%$ \\
Crédito na loja & 11 & 3,36 & $36,4 \%$ \\
Correção insatisfatória & 37 & 2,57 & $62,2 \%$ \\
A tentativa de recuperação piorou a situação & 50 & 2,36 & $42,0 \%$ \\
Não-recuperação & 114 & 1,55 & $31,0 \%$ \\
\hline Total & $\mathbf{6 6 1}$ & $\mathbf{5 , 8 8}$ & $\mathbf{7 1 , 2 \%}$ \\
\hline
\end{tabular}

*As recuperações foram avaliadas numa escala de 1 (muito ruim) a 10 (muito bom).

**O percentual de retenção é a razão entre o número de entrevistados que indicaram que continuariam comprando na loja envolvida no incidente e o número de incidentes relatados. 
Esses resultados parecem indicar a importância da estratégia de recuperação de serviços para o varejo de bens, pois as situações nas quais o varejista nada fez foram as que tiveram as piores avaliações por parte dos clientes.

\section{A Pesquisa no Brasil}

A metodologia utilizada no presente estudo foi a da Técnica de Incidente Crítico (Bitner, Booms e Tetreault, 1990), que permite a investigação e a compreensão de situações críticas de forma detalhada. Esse método consiste em um conjunto de procedimentos utilizados para coletar, analisar e classificar observações do comportamento humano em um incidente crítico, que se caracteriza como uma situação em que se desvia, tanto positiva quanto negativamente, do que seria normal ou esperado acontecer (Kelley, Hoffman e Davis, 1993). Estudos anteriores mostraram a confiabilidade e a validade da metodologia aplicada à pesquisa sobre a reação de clientes aos encontros de serviço (Bitner, Booms e Tetreault, 1990).

Para se proceder ao levantamento de falhas e estratégias de recuperação recorrentes no varejo brasileiro e seu impacto sobre a satisfação e retenção de clientes, foi desenvolvido um instrumento de coleta que permitiu que as pessoas envolvidas descrevessem a falha ocorrida e a estratégia de recuperação aplicada, bem como fizessem uma avaliação do impacto da iniciativa de recuperação tanto sobre a sua satisfação com os serviços do varejista quanto sobre o seu padrão de repetição de uso posterior. O questionário aplicado foi elaborado a partir do modelo utilizado por Kelley, Hoffman e Davis (1993). Na aplicação do questionário evitou-se dar exemplificações de falhas e estratégias de recuperação no varejo de bens, de modo a não direcionar a resposta do consumidor (Lapidus e Schibrowsky, 1994). O trabalho de campo foi realizado durante o quarto trimestre de 2000.

A amostra utilizada foi de conveniência, prática amplamente adotada na aplicação do método do incidente crítico (Bitner, Booms e Tetreault, 1990; Kelley, Hoffman e Davis, 1993; Grove e Fisk, 1997). Os questionários foram aplicados ao maior número possível de pessoas dentro de um prazo predeterminado para a coleta de dados, nas cidades do Rio de Janeiro e de São Paulo, utilizando-se alunos de Mestrado em Administração como entrevistadores (Bitner, Booms e Tetreault, 1990; Grove e Fisk, 1997). Dadas as suas características, não se consideraram os resultados desse estudo passíveis de generalização para além da amostra estudada, ou seja, para outros contextos e serviços. 
Foram obtidos 248 questionários respondidos, dos quais 224 puderam ser aproveitados. Os questionários eliminados descreviam incidentes críticos de outros setores que não o do varejo de bens ou eram ambíguos ou confusos em seus relatos. Das 224 respostas, 86 descreveram estratégias de recuperação satisfatórias e 138 estratégias de recuperação insatisfatórias.

É preciso identificar e comentar algumas limitações metodológicas. A primeira é inerente à Técnica do Incidente Crítico, método de pesquisa sujeito à subjetividade do pesquisador. Este pode não ter sensibilidade teórica suficiente ou pode basear-se em idéias preconcebidas ao analisar e interpretar os dados, conduzindo a resultados nem sempre confiáveis. Dessa forma, no âmbito deste trabalho, uma das limitações está relacionada com a classificação dos incidentes críticos nas diferentes categorias de falhas e de estratégias de recuperação. Outra limitação diz respeito ao processo de amostragem de conveniência, tendo como universo de pesquisa consumidores das regiões metropolitanas do Rio de Janeiro e de São Paulo. Além de não ser uma amostra estatisticamente representativa, os resultados obtidos devem ser considerados apenas para aquelas duas regiões do país. Finalmente cabe mencionar uma limitação relacionada à não fixação de um período determinado de tempo para a análise dos incidentes críticos. Mesmo solicitando aos entrevistados que indicassem a data da ocorrência do incidente, muitos não a mencionaram. Acredita-se que os consumidores tendem a relatar casos recentes, mas não é possível afirmar que as falhas e/ou estratégias de recuperação aqui identificadas são correntes.

As características demográficas da amostra de consumidores envolvidos na pesquisa são apresentadas na Tabela 1. Em relação ao nível de escolaridade, 204 consumidores tinham nível superior completo $(91,07 \%)$ e os outros 20 consumidores (8,93\%) tinham o $3^{\circ}$ grau incompleto.

Tabela 1: Características Demográficas da Amostra

\begin{tabular}{c|c|c|c|c|c|c|c}
\hline \multicolumn{2}{c|}{ SEXO } & \multicolumn{6}{c}{ IDADE } \\
\hline Feminino & Masculino & $<$ de 21 & 21 a 25 & 26 a 35 & 36 a 45 & 46 a 55 & > de 55 \\
\hline 126 & 98 & 4 & 30 & 74 & 64 & 44 & 8 \\
\hline $56,25 \%$ & $43,75 \%$ & $1,79 \%$ & $13,39 \%$ & $33,04 \%$ & $28,57 \%$ & $19,64 \%$ & $3,57 \%$ \\
\hline
\end{tabular}




\section{Apresentação e Análise dos Resultados}

\section{Classificação e Análise de Falhas no Varejo de Bens}

Os resultados referentes às falhas identificadas nesta pesquisa e categorizadas segundo a tipologia de Kelley, Hoffman e Davis (1993) são apresentados na Tabela 2, discutindo-se, a seguir, os resultados para cada um dos 15 subgrupos de falhas.

Tabela 2: Classificação de Falhas no Varejo de Bens

\begin{tabular}{|c|c|c|}
\hline Tipos de Falhas & $\begin{array}{l}\text { Número de vezes em que o } \\
\text { incidente foi citado }\end{array}$ & $\begin{array}{c}\% \text { sobre o total de } \\
\text { falhas }\end{array}$ \\
\hline \multicolumn{3}{|c|}{$\begin{array}{l}\text { Grupo 1: Respostas dos funcionários a } \\
\text { problemas no sistema de prestação }\end{array}$} \\
\hline Falhas na política da empresa & 30 & $13,39 \%$ \\
\hline Serviços lentos/indisponíveis & 40 & $17,86 \%$ \\
\hline Erros no sistema de precificação & 22 & $9,82 \%$ \\
\hline Erros de embalagem & 0 & $0 \%$ \\
\hline Falta de produto & 24 & $10,71 \%$ \\
\hline Produtos com defeitos & 46 & $20,54 \%$ \\
\hline Problemas na reserva de mercadoria & 0 & $0 \%$ \\
\hline Erros durante os reparos efetuados & 8 & $3,57 \%$ \\
\hline Má informação & 8 & $3,57 \%$ \\
\hline Total - Grupo 1 & 178 & $79,46 \%$ \\
\hline \multicolumn{3}{|c|}{$\begin{array}{l}\text { Grupo 2: Respostas dos funcionários a } \\
\text { necessidades e pedidos dos clientes }\end{array}$} \\
\hline Pedidos/Requisições & 4 & $1,79 \%$ \\
\hline Erros dos Clientes & 8 & $3,57 \%$ \\
\hline Total - Grupo 2 & 12 & $5,36 \%$ \\
\hline \multicolumn{3}{|l|}{$\begin{array}{l}\text { Grupo 3: Atitudes imprevisíveis e não } \\
\text { desejadas dos funcionários }\end{array}$} \\
\hline Cobrança indevida & 10 & $4,46 \%$ \\
\hline Acusação de roubo & 2 & $0,89 \%$ \\
\hline Situações constrangedoras & 4 & $1,79 \%$ \\
\hline Falha de atenção & 18 & $8,04 \%$ \\
\hline Total - Grupo 3 & 34 & $15,18 \%$ \\
\hline TOTAL GERAL & 224 & $100,00 \%$ \\
\hline
\end{tabular}

. Subgrupo 1 - Falhas na política. São falhas resultantes de políticas inadequadas do varejista. Segundo a percepção dos clientes, em todas as falhas neste subgrupo, os funcionários desempenharam as suas funções de acordo com as normas da empresa. Além de problemas com políticas de troca, os clientes rela- 
taram falhas decorrentes de falta de ética na cobrança e na forma de pagamento (8 falhas) e de políticas pouco voltadas ao atendimento ao cliente (4 falhas). Entre as 30 falhas classificadas neste subgrupo, 14 envolveram tentativas de troca de mercadorias para as quais o varejista tinha uma política rígida que não atendia às necessidades dos clientes. Mesmo que, em algumas situações, o incidente tenha resultado na troca de mercadoria desejada, os clientes guardaram a imagem de que a política do varejista era inadequada, o que lhes exigia grande esforço para garantirem os seus direitos.

. Subgrupo 2 - Serviços lentos/indisponíveis. Entre as 40 falhas classificadas nesta categoria, 14 relataram problemas com atendimento, seja pela falta de funcionários disponíveis, seja pelo seu despreparo para lidar com os clientes, sendo os problemas com o sistema de pagamento os mais recorrentes. Vinte e quatro falhas relataram a lentidão do sistema ou a falta de preparo dos funcionários para processar pagamentos com cartão de crédito ou cartão de débito automático e para a obtenção de crediários. Em muitos casos, os clientes atribuíram a culpa à lentidão dos sistemas de informação, internos ou externos à empresa. Por fim, duas falhas relataram problemas de serviços indisponíveis: uma referente ao serviço de embrulho para presentes e outra alusiva à falta de carregador em supermercado para auxiliar na condução das compras até o carro.

. Subgrupo 3 - Falhas no sistema de precificação. Essas falhas foram resultantes de dois erros típicos do varejista: ou o preço do produto estava mal afixado na prateleira, levando o cliente a ver o preço errado (10 falhas), ou o produto tinha um preço afixado na prateleira e outro registrado no sistema para leitura automática do código de barras (12 falhas).

. Subgrupo 4 - Erros de embalagem. Nenhuma das falhas relatadas no presente estudo pôde ser classificada nesta categoria. Seriam falhas decorrentes de erros do varejista ao fazer embrulhos e embalagens para os clientes.

. Subgrupo 5 - Falta de produto. Esta categoria incluiu as situações nas quais o cliente foi até a loja comprar um produto ou item específico e não o encontrou. Dos 24 incidentes incluídos neste subgrupo, 16 relataram ocasiões em que, apesar de anunciados em encartes promocionais ou expostos em vitrines e áreas de apresentação, não havia produtos em estoque para venda ou estes não estavam disponíveis ou acessíveis para o cliente. Nas 8 falhas restantes, o cliente apenas não encontrou o produto que desejava.

. Subgrupo 6 - Produto defeituoso. Nesta categoria foram classificadas as falhas referentes a problemas diretamente relacionados aos produtos adquiridos. É interessante observar que dos 46 incidentes relatados, 26 referiram-se a problemas com produtos de marcas que não pertenciam ao varejista, ou seja, falhas 
que, a princípio, não seriam deles. Entretanto, mesmo reconhecendo que o problema de qualidade original era do fabricante, os clientes atribuíam uma parcela de culpa também aos varejistas, por estarem comercializando produtos sem qualidade adequada. As outras 20 falhas relatadas referiram-se a problemas de produtos de varejistas verticalizados, ou seja, o varejista era, ao mesmo tempo, fabricante e revendedor.

. Subgrupo 7 - Problemas na reserva. Assim como no subgrupo 4, nenhuma das falhas relatadas no presente estudo pôde ser classificada nesta categoria, a qual, no estudo-base, incluía falhas decorrentes de erros do varejista ao fazer reservas de produtos.

. Subgrupo 8 - Alteraç̃̃es e reparos. Aqui foram classificadas as falhas decorrentes de erros durante o reparo de produtos. Das 8 falhas registradas, 3 foram decorrentes de demora nos reparos, enquanto 5 descreveram situações nas quais os reparos foram mal executados.

. Subgrupo 9 - Má informação. Nesta categoria, as falhas incluíram situações em que os clientes receberam informações que pesaram sobre as suas decisões de compra, as quais, ao terem de ser utilizadas, mostraram-se incorretas. As 8 falhas incluídas nesta categoria descreveram situações nas quais os clientes se sentiram enganados pelos varejistas ao adquirirem um produto.

. Subgrupo 10 - Pedidos e requisições. Os incidentes classificados nesta categoria envolveram problemas com mercadorias feitas sob encomenda. As 4 falhas relatadas descreveram situações de atraso na entrega.

. Subgrupo 11 - Erros de clientes. Os incidentes classificados nesta categoria incluíram situações nas quais os clientes assumiram a sua culpa pelo erro ocorrido. Das 8 falhas relatadas nesta categoria, 6 envolveram situações em que o cliente adquiriu o produto no tamanho errado, seja por não ter experimentado o produto quando podia fazê-lo, seja por ter pedido o tamanho errado no ato da compra.

. Subgrupo 12 - Cobrança indevida. As falhas classificadas neste subgrupo ocorreram em função de erros de funcionários e não do sistema. Das 10 falhas relatadas, 6 envolveram situações nas quais valores cobrados no cartão de crédito estavam errados, 3 consistiram em problemas com troco e uma envolveu o esquecimento, por parte de um funcionário, de eliminar o débito de um cliente do sistema de dados da empresa, fazendo com que ele fosse novamente cobrado por um valor que já havia pago cada vez que retornava à loja.

. Subgrupo 13 - Acusação de roubo. Nesta categoria foram incluídas duas 
falhas que consistiram em incidentes nos quais os clientes foram injustamente acusados de roubo.

. Subgrupo 14 - Situações constrangedoras. Os incidentes classificados neste subgrupo envolveram situações nas quais os funcionários cometeram erros graves, criando constrangimentos para o cliente. Três das quatro falhas ocorreram porque o funcionário esqueceu de retirar do produto o sistema magnético antifurto, que apitou quando o cliente deixou a loja. A outra situação descrita foi a de um cliente acusado de ter saldo devedor com a loja e, por conta disso, exposto ao opróbrio diante de outros clientes, quando na verdade nada estava devendo.

. Subgrupo 15 - Falha de atenção. Aqui foram classificadas as falhas decorrentes de situações em que o cliente não recebeu a atenção desejada por pura negligência dos funcionários e não por indisponibilidade deles, como ocorreu no subgrupo 2. Dezoito falhas foram identificadas, sendo que 12 referentes a situações nas quais os funcionários ignoraram a presença dos clientes e continuaram conversando entre si ou falando ao telefone. As outras 6 falhas consistiram em situações nas quais os funcionários foram rudes e mal-educados.

Dada a limitada amplitude desta pesquisa, o fato de não terem sido encontrados erros de embalagem e problemas na reserva de mercadorias não significa que essas falhas não ocorram no mercado brasileiro; entretanto isso pode ser indicação de que essas falhas aconteçam em menor freqüência que as demais, ou ainda que tenham impacto menor na ótica dos clientes, que acabam esquecendoas e deixando de mencioná-las em uma pesquisa como a presente.

\section{Classificação e Análise das Estratégias de Recuperação}

Os resultados relativos às estratégias de recuperação identificadas nos relatos de incidentes críticos são apresentados na Tabela 3.

Todas as 224 estratégias de recuperação identificadas puderam ser classificadas em uma das categorias da tipologia de Kelley, Hoffman e Davis (1993) já comentada; no entanto é interessante ressaltar que esta pesquisa não identificou nenhuma estratégia de recuperação que pudesse ser classificada na categoria de recuperações baseadas no oferecimento de crédito na loja, subgrupo 9 daquela tipologia. 


\section{Tabela 3: Estratégias de Recuperação}

\begin{tabular}{|c|c|c|c|c|c|c|}
\hline Categoria Recuperação & Quantidade & $\%$ do Total & $\begin{array}{l}\text { Avaliação da } \\
\text { Recuperação* }\end{array}$ & $\begin{array}{l}\text { Resultado } \\
\text { Ruim }\end{array}$ & $\begin{array}{c}\text { Resultado } \\
\text { Bom }\end{array}$ & $\begin{array}{c}\text { Retenção } \\
\% * * *\end{array}$ \\
\hline 1. Desconto & 4 & $1,79 \%$ & $\begin{array}{l}5,50 \\
(0,58)^{* *}\end{array}$ & 0 & 4 & $\begin{array}{l}75,0 \% \\
(3 / 4)\end{array}$ \\
\hline 2. Correção & 36 & $16,07 \%$ & $\begin{array}{c}6,67 \\
(2,08)\end{array}$ & 4 & 32 & $\begin{array}{c}88,9 \% \\
(32 / 36)\end{array}$ \\
\hline $\begin{array}{l}\text { 3. Intervenção do Gerente / } \\
\text { Empregado }\end{array}$ & 8 & $3,57 \%$ & $\begin{array}{c}5,75 \\
(1,91)\end{array}$ & 2 & 6 & $\begin{array}{l}75,0 \% \\
(6 / 8)\end{array}$ \\
\hline 4. Correção Plus & 10 & $4,46 \%$ & $\begin{array}{c}7,60 \\
(1,71)\end{array}$ & 0 & 10 & $\begin{array}{l}100,0 \% \\
(10 / 10)\end{array}$ \\
\hline 5. Troca & 24 & $10,71 \%$ & $\begin{array}{c}8,25 \\
(2,33)\end{array}$ & 4 & 20 & $\begin{array}{c}91,7 \% \\
(22 / 24)\end{array}$ \\
\hline 6. Desculpas & 10 & $4,46 \%$ & $\begin{array}{c}5,00 \\
(3,53)\end{array}$ & 4 & 6 & $\begin{array}{l}60,0 \% \\
(6 / 10)\end{array}$ \\
\hline 7. Reembolso & 6 & $2,68 \%$ & $\begin{array}{c}3,67 \\
(0,52)\end{array}$ & 6 & 0 & $\begin{array}{l}33,3 \% \\
(2 / 6)\end{array}$ \\
\hline 8. Cliente Iniciou a Correção & 28 & $12,50 \%$ & $\begin{array}{c}2,14 \\
(1,33)\end{array}$ & 26 & 2 & $\begin{array}{l}21,4 \% \\
(6 / 28)\end{array}$ \\
\hline 9. Crédito na Loja & 0 & $0,00 \%$ & - & - & - & - \\
\hline 10. Correção Insatisfatória & 20 & $8,93 \%$ & $\begin{array}{c}3,00 \\
(1,78)\end{array}$ & 14 & 6 & $\begin{array}{l}30,0 \% \\
(6 / 20)\end{array}$ \\
\hline 11. Potenciação da Falha & 10 & $4,46 \%$ & $\begin{array}{l}1,20 \\
(0,42)\end{array}$ & 10 & 0 & $\begin{array}{c}0,0 \% \\
(0 / 10)\end{array}$ \\
\hline 12. Não Recuperação & 68 & $30,36 \%$ & $\begin{array}{c}1,50 \\
(0,98)\end{array}$ & 66 & 2 & $\begin{array}{c}11,8 \% \\
(8 / 68)\end{array}$ \\
\hline Total & 224 & $100,00 \%$ & $\begin{array}{c}3,89 \\
(3,06)\end{array}$ & 136 & 88 & \\
\hline
\end{tabular}

* As recuperações foram avaliadas numa escala de 1 (muito ruim) a 10 (muito bom).

** Desvio padrão está apresentado entre parênteses.

*** O percentual de retenção é a razão entre o número de entrevistados que indicaram que continuariam comprando na loja envolvida no incidente e o número de incidentes relatados.

. Recuperação 1 - Desconto. Esta estratégia de recuperação consiste na oferta de um desconto como forma de compensar os clientes por problemas ocorridos. Nos 224 incidentes relatados, ela foi aplicada apenas 24 vezes. Apesar da baixa freqüência desse recurso, há indicação de que esta é uma estratégia percebida de maneira relativamente positiva pelo cliente, dado que a sua avaliação média foi de 5,50 e a taxa de retenção correspondente de 75\%.

. Recuperação 2 - Correção. Esta estratégia caracteriza-se pela simples correção do erro cometido. Foi a estratégia mais mencionada nos relatos de incidentes críticos (36 vezes), sendo positivamente avaliada pelos clientes, que lhe conferiram uma avaliação média de 6,67. Além disso, obteve alta taxa correspondente de retenção de clientes, em torno de 88,9\%.

. Recuperação 3 - Intervenção do gerente/outro empregado. Esta estratégia refere-se a situações de recuperação em que é necessária a intervenção do gerente ou de outro funcionário para que o problema possa ser resolvido ou corrigido. Em geral, os clientes têm uma percepção positiva dessa estratégia, o que 
se confirma quando se verifica que, em seis das oito vezes em que foi mencionada, recebeu uma avaliação acima de 5. Entretanto os resultados revelam que é menos eficaz do que a estratégia de correção, pois recebeu como média de avaliação a nota 5,75 , sendo de $75 \%$ a sua taxa correspondente de retenção de clientes. Isso poderia ser explicado por uma preferência dos clientes por terem seus problemas resolvidos o mais rapidamente possível, sem a necessidade de interferência de terceiros (Lovelock,1996).

. Recuperação 4 - Correção plus, ou correção com algo mais. Esta estratégia inclui situações nas quais os varejistas foram além da correção simples, oferecendo algum tipo de compensação adicional ao cliente. Tendo sido mencionada 10 vezes, esta estratégia foi muito bem percebida e avaliada pelo cliente, proporcionando uma taxa de retenção de $100 \%$. Este procedimento pode ser traduzido como encantar o cliente e, por isso, recebeu uma das melhores avaliações, acima da correção simples.

. Recuperação 5 - Troca. Esta estratégia consiste na troca de mercadorias, defeituosas ou não, e foi encontrada 24 vezes na amostra. Esta foi a estratégia mais bem avaliada pelos clientes, com uma nota média de 8,25 e uma taxa correspondente de retenção de $91,7 \%$.

. Recuperação 6 - Desculpas. Esta estratégia consiste num pedido de desculpas. Ela foi utilizada em 10 ocasiões e a sua avaliação não foi uma das melhores, embora possa ser considerada positiva, pois a sua nota-média foi 5,00 e a sua taxa correspondente de retenção de $60 \%$. Esse resultado mediano justifica-se pelo fato de que o pedido de desculpas, ao mesmo tempo que mostra preocupação do varejista com os problemas do consumidor, nem sempre resolve a questão, ficando aquém das expectativas dos clientes.

. Recuperação 7 - Reembolso. Mencionada apenas 6 vezes, esta estratégia envolve as iniciativas de se oferecer um reembolso no caso da ocorrência de problemas. A sua avaliação média de 3,67 e a retenção de 33,3\% poderiam se justificar pelo fato de que, muitas vezes, há resistência por parte do varejista em efetuar o reembolso, o que acabaria prejudicando a percepção do cliente.

. Recuperação 8 - Cliente iniciou a correção. Para ser incluída nesta categoria, a estratégia de recuperação teve de ter o cliente como força propulsora do resultado. Isso significa que o varejista só corrigiu a situação após muito esforço do cliente em defender-se e expor o problema. Os resultados desfavoráveis em termos de recuperação e retenção (avaliação média de 2,14 e retenção de 21,4\%) revelam que esta é uma estratégia negativamente percebida pelo cliente. No entanto, a freqüência da sua ocorrência foi destacada na amostra analisada, tendo ocupado a segunda posição como estratégia mais utilizada. 
. Recuperação 10 - Correção insatisfatória. Esta situação, na verdade, consiste em uma tentativa mal elaborada de recuperar a satisfação do cliente, o que resulta em correção insatisfatória. O cliente reconhece que o varejista tenta reparar o erro, mas não atinge as suas expectativas. Nos 224 incidentes relatados, esta estratégia foi utilizada 20 vezes e não foi bem avaliada pelos clientes, ficando com avaliação média de 3,00 e uma taxa de retenção de 30\%.

. Recuperação 11 - Potenciação da falha. Nestes casos, o varejista, ao tentar recuperar a satisfação do consumidor, acaba cometendo novos erros e potenciando os efeitos da falha. Pode ser vista como estratégia altamente negativa sob a perspectiva do cliente, tendo recebido uma avaliação média de 1,20 e uma taxa de retenção de $0 \%$.

. Recuperação 12 - Não-recuperação. Aqui estão englobadas as situações em que o varejista nada fez para recuperar a satisfação do cliente. Esta foi de longe a resposta mais freqüente dos varejistas nos incidentes relatados (30\% dos casos) e, ao mesmo tempo, uma das que recebeu as piores avaliações dos clientes, ficando com uma nota-média de 1,50 e uma taxa correspondente de retenção de 11,8\%.

Os resultados relativos às estratégias de recuperação, ilustrados na Tabela 3, revelam alguns aspectos interessantes tanto no que diz respeito à prática da recuperação de serviços no varejo de bens brasileiro, mais especificamente no Rio de Janeiro e em São Paulo, quanto em relação ao quadro conceitual utilizado. Em primeiro lugar, apontam quais são as estratégias de recuperação bem avaliadas pelos clientes do varejo de bens nos mercados estudados e quais aquelas que não os satisfazem. Estratégias como correção, correção com compensação e troca de produto foram muito bem avaliadas e tiveram elevadas taxas correspondentes de retenção de clientes. Trata-se de três estratégias em que o varejista termina a prestação original do serviço da forma como o cliente gostaria, admitindo o erro que cometeu e mostrando-lhe que entende o problema sob a sua perspectiva, dado que é capaz de corrigí-lo. A correção plus, ou a correção acrescida de compensação, inclui ainda a diretriz de oferecer algo a mais no caso das falhas mais graves.

As estratégias de desconto, intervenção do gerente ou de outro funcionário e as desculpas foram medianamente avaliadas, e as suas taxas de retenção foram razoáveis. A estratégia de desculpas, em especial, mostrou-se efetiva em algumas situações. Entretanto, com relação a falhas para as quais os clientes esperam ver uma alteração de resultados, ela não se mostra eficaz. Isso parece corroborar a afirmação de muitos autores no sentido de que a recuperação de serviços deve focar a resolução de problemas, pois é isso que os clientes esperam, mesmo que uma recompensa, um desconto ou um pedido de desculpas possam 
ser oferecidos a mais, como o que ocorre na correção plus, ou seja, a correção com algo a mais. Caso um tanto diverso é o da estratégia de reembolso, cuja avaliação e taxa correspondente de retenção foram baixas. No entanto, tanto na estratégia de reembolso quanto na de desconto, que significam uma compensação financeira por uma falha ocorrida que não pôde ser resolvida, evidenciou-se na análise dos relatos que não é em qualquer situação que os consumidores estão dispostos a aceitar uma recompensa financeira, chegando a sentir-se, algumas vezes, ofendidos com a oferta.

Os resultados relativos à estratégia de intervenção de um gerente ou de outro funcionário revelam que os clientes do varejo valorizam a rapidez da resolução e a forma como seus problemas estão sendo tratados. O fato de haver a necessidade da intervenção de uma terceira pessoa para a resolução de uma falha retarda o processo, mesmo que traga os resultados desejados pelo cliente. Da mesma forma, este processo pode criar situações que transmitam a idéia de que a empresa, na pessoa do funcionário ou vendedor, está duvidando do cliente e de que é necessária a intervenção de uma terceira parte para julgar a situação.

Por fim, as situações em que o cliente teve de iniciar o processo de recuperação, a correção foi insatisfatória, houve potenciação da falha ou ainda em que a empresa nada fez foram julgadas como insuficientes pelos clientes, correspondendo-lhes baixas taxas de retenção; no entanto, analisando-se essas estratégias, verifica-se que, na verdade, elas não o são. Ou seja, empresas nas quais o cliente é que tem de impulsionar fortemente uma correção, em que as correções são insatisfatórias e os funcionários não são capazes de resolver os problemas e acabam piorando a situação, ou ainda onde nada é feito, são empresas que não têm um sistema de recuperação de serviços planejado e elaborado. Na maior parte das vezes, essas empresas nada fazem para corrigir as falhas e, quando são forçadas a fazê-lo, por muita insistência do cliente, acabam mostrando que são incompetentes na correção de problemas e, não raro, pioram a situação.

De fato é digno de nota que, dos 224 casos relatados, 126 (aproximadamente 67\%) dão conta de situações em que as empresas não tinham implementado um sistema de recuperação de serviços. É interessante observar ainda que a correção insatisfatória do problema ou aquela realizada sob forte pressão do cliente ainda é mais bem avaliada por eles do que a situação em que o varejista nada faz. Isso demonstra que os clientes têm, via de regra, uma expectativa de que as empresas reajam diante de falhas, mesmo que de maneira pouco planejada.

Finalmente, os resultados apresentados na Tabela 3 expressam o impacto das diferentes estratégias na retenção de clientes. As estratégias mais bem avaliadas pelos clientes foram as que resultaram nas mais altas taxas de retenção. Por 
outro lado, as estratégias que indicam a inexistência de um sistema estruturado de recuperação de serviços foram em geral mal avaliadas e tiveram baixa taxa de retenção de clientes. Isso reforça os argumentos quanto ao impacto da satisfação do cliente no seu padrão de fidelidade, destacado na Cadeia do Lucro em Serviços, sugerida por Heskett, Sasser e Schlesinger (1994), assim como a influência que a recuperação de serviços tem sobre a própria satisfação dos clientes e, por conseqüência, sobre sua retenção (Hart, Heskett e Sasser, 1990).

\section{Conclusões}

Algumas conclusões interessantes a respeito das falhas e da prática da recuperação de serviços no varejo de bens no Brasil podem ser traçadas a partir dos resultados deste estudo.

Inicialmente, em relação às falhas, os resultados indicam que 79,46\% decorreram de respostas de funcionários a problemas do sistema de prestação de serviços, ou seja, são enquadráveis no grupo 1 de Bitner, Booms e Tetreault (1990). Ao contrário daquelas provenientes de respostas dos funcionários a pedidos específicos de clientes (grupo 2) ou de atitudes imprevisíveis e inesperadas dos funcionários (grupo 3), as falhas classificadas no grupo 1 não são inevitáveis ou imprevisíveis, dado que são inerentes ao próprio sistema de prestação do serviço.

Dessa forma, o que os resultados deste estudo sugerem é que o varejo de bens no Brasil, mais especificamente no Rio de Janeiro e em São Paulo, sofre de problemas de qualidade que poderiam ser evitados com bom planejamento na área. As empresas que atuam neste setor devem, portanto, observar essa questão com mais cuidado, principalmente no momento atual em que se observa a chegada ao mercado brasileiro de cadeias de varejo de atuação global, como a Wal-Mart e a JCPenney, entre muitas outras, cujo sucesso em outros contextos decorre das suas operações com elevados padrões de qualidade.

Dentro do grupo 1, as falhas relativas a produtos defeituosos, serviços lentos e indisponíveis, políticas inadequadas, falta de produto e sistemas de precificação, nessa ordem, foram as relatadas com maior freqüência pela amostra estudada. Embora tais resultados não possam ser generalizados, trata-se de um alerta de que estes problemas ocorrem com certa freqüência, merecendo uma observação mais de perto pelos varejistas.

Para os produtos defeituosos, os resultados revelam que os clientes atribuem culpa ao varejista pela venda de um produto de baixa qualidade, mesmo que este 
não seja da sua fabricação. Assim, as empresas varejistas devem ter muito cuidado na escolha dos produtos que irão oferecer e, ao mesmo tempo, serem exigentes com seus fornecedores, sobretudo ao descobrirem problemas com algum produto que comercializam. Além disso, o varejista deve ainda estabelecer políticas de troca adequadas às necessidades dos clientes, de modo a permitir-lhes substituir facilmente o produto comprado, uma vez que tenha surgido um problema com ele. De fato, disso parece depender a imagem de qualidade que o varejista desejaria construir.

Ao se analisarem os resultados relativos às falhas decorrentes de serviços lentos ou indisponíveis, verifica-se elevado índice de incidentes, envolvendo sistemas de pagamento. Esse é um problema que deve preocupar os varejistas, porquanto, em muitos casos, a culpa é de um sistema de transmissão de dados ainda precário, que nada tem a ver especificamente com as suas operações. Sabedores de que esses problemas podem ocorrer, os varejistas devem orientar o seu pessoal da linha de frente a esclarecer a questão junto aos clientes e propor soluções alternativas de pagamento. Além disso, os relatos de falhas referentes a serviços lentos e indisponíveis revelam ainda que as empresas que atuam no varejo de bens, nos mercados analisados, muitas vezes sofrem de falta de pessoal ou operam com pessoas incapacitadas para a prestação do serviço. Esses resultados comprovam a influência que o pessoal de contato tem sobre a percepção de qualidade dos clientes em relação ao serviço no varejo de bens, dado que a falta de pessoal ou a sua pouca habilidade provocam insatisfação nos clientes. A mesma conclusão é válida para as falhas resultantes de atitudes imprevisíveis e não desejadas dos funcionários, caracterizadas pela falta de atenção ou atenção inadequada. A incapacidade de oferecer ao cliente o serviço de atendimento esperado é diretamente resultante de problemas com o treinamento, com a capacitação de funcionários e com vendedores do varejo. Mais uma vez fica claro que os varejistas devem ter consciência de que as pessoas de contato têm um impacto determinante na experiência do cliente e, dessa forma, devem prover-lhes todo o suporte para que possam atuar de modo positivo sobre a satisfação dos clientes.

A falta de produtos também apareceu com certa freqüência no relato dos clientes. Essa é falha grave não só pela insatisfação que provoca nos clientes como também por representar perda de vendas e faturamento. Isso se agrava quando os produtos faltosos estão anunciados em encartes promocionais. Controle de estoque bem afinado e trabalho conjunto entre operações e vendas podem evitar a ocorrência dessas falhas.

Os problemas com sistemas de precificação também foram relatados com freqüência significativa. Os resultados revelam que os varejistas estão tendo proble- 
mas para a fixação dos preços em prateleiras ou os próprios clientes ainda não estão adaptados a esse sistema. É necessário que os preços estejam claramente afixados, de modo a se evitarem confusões ou frustrações para o cliente.

Os resultados decididamente revelaram três estratégias de sucesso na recuperação de serviço: a correção simples de falhas, a correção adicionada de compensação (correção plus) e a troca de produtos. Essas estratégias mostraram ter impacto positivo sobre a satisfação e a retenção de clientes e, por isso, podem ser aplicadas por empresas varejistas que buscam desenvolver um sistema de recuperação de serviços eficaz. O fato de estratégias como a correção ou a troca de produtos terem sido bem avaliadas pelos clientes parece corroborar as indicações na literatura de que, na recuperação de serviço, o que o cliente em geral quer é ter o resultado que inicialmente esperava, ou seja, gostaria de receber o serviço originalmente proposto. Isso implica que a recuperação não deve consistir em atitudes heróicas e grandiosas, mas de atos firmes e decisivos para atingir o benefício desejado pelo cliente.

Este estudo identificou também estratégias de recuperação de serviço que devem ser adotadas com cautela, no caso de serviços de varejo de bens. É o caso de estratégias como reembolsos e descontos, pedidos de desculpas e interferência de gerentes na resolução de problemas. Os resultados relacionados com as práticas de descontos e reembolsos revelam que, nem sempre, os consumidores estão dispostos a aceitar uma recompensa financeira por um problema ocorrido e que, em alguns casos, sentem que as empresas querem comprar a sua satisfação. Já a intervenção de um gerente foi medianamente avaliada pelos clientes, o que sugere que eles valorizam mais a resolução de problemas simples e rápida. Quando se compara esta estratégia àquela de correção, verifica-se que a diferença básica está na forma como a recuperação foi conduzida e não no resultado. A interferência de terceiros torna o processo mais prolongado, e o cliente fica mais exposto a tensões e discussões. Quando os problemas são simples, o cliente espera que o próprio vendedor ou funcionário com quem está interagindo seja capaz de solucionar a questão. Isso tem implicação direta no preparo e na formação com que as empresas do varejo devem prover o seu pessoal que tem contato direto com o público, sendo a delegação de poderes uma estratégia a ser aplicada.

Os resultados revelam também que o pedido de desculpas é bem recebido pelos clientes, mas não é suficiente como estratégia de resolução de problemas. Os clientes querem ter seus problemas solucionados, e um pedido de desculpas isolado, na maioria das vezes, nada resolve. Os varejistas devem orientar seus funcionários a se desculparem pelos transtornos, mas não devem apoiar-se no pedido de desculpas para recuperar a satisfação dos clientes. 
Além disso, os resultados da pesquisa apontaram ainda atitudes das empresas varejistas em resposta a falhas que não podem ser consideradas como estratégias de recuperação, mas, ao contrário, revelam o despreparo de algumas empresas desse setor para o tratamento de problemas. As não-estratégias identificadas foram situações nas quais o cliente teve de pressionar o varejista para que tomasse alguma atitude diante da falha, em que o varejista fez uma correção insatisfatória, nas quais as atitudes tomadas acabaram intensificando as impressões negativas das falhas originais ou, ainda, nas quais ignorou a falha e nada fez. É surpreendente a observação de que aproximadamente 67\% dos questionários relataram situações em que as empresas não tinham um sistema de recuperação de serviços bem planejado. Mesmo considerando-se as limitações da pesquisa, este percentual elevado sugere que as empresas que atuam no varejo de bens no Brasil, mais especificamente no Rio de Janeiro e em São Paulo, ainda têm muito a desenvolver no que diz respeito à recuperação de serviços. Uma comparação entre os resultados deste estudo e os realizados por Kelley, Hoffman e Davis (1993) no mercado norte-americano, revela que as empresas brasileiras se encontram mais atrasadas no desenvolvimento de sistemas de recuperação de serviços do que as empresas naquele mercado, naquela época.

Por fim, os resultados desta pesquisa sugerem ainda que a recuperação de serviços tem impacto positivo na retenção de clientes no varejo de bens. As estratégias de recuperação bem avaliadas pelos clientes, quando aplicadas, resultaram em boas taxas de retenção. Às não-estratégias, por outro lado, corresponderam pequenas taxas de retenção de clientes, sendo este um ponto a ser observado pelas empresas de varejo de bens no país, em busca de melhores resultados, em termos de lucratividade e participação no mercado.

\section{RefERÊnCIAS Biblográficas}

BATESON, J. E. G.

Managing services marketing: text and readings. 3. ed. Orlando, FL: The Dryden Press, 1995.

BITNER, M. J.;

BOOMS, B. H.;

TETREAULT, M. S.

The service encounter: diagnosing favorable and unfavorable incidents. Journal of Marketing, v. 54, n. 1, p. 71-84, Jan. 1990.

GRÖNROOS, C.

Marketing, gerenciamento e serviços: a competição por serviços na hora da verdade. Rio de Janeiro: Campus, 1995. 
GROVE, S. J.;

FISK, R. P.

The impact of other customers on service experiences: a critical incident examination of "getting along”. Journal of Retailing, $v$. 73, n. 1, p. 63-85, Spring 1997.

HART, C. W. L.;

HESKETT, J. L.;

SASSER JR., W. E.

The profitable art of service recovery. Harvard Business Review, v. 68, n. 4, p. 148-156, July/Aug. 1990.

HAYS, J. M.;

HILL, A. V.

The market share impact of service failures. Production and Operations Management, v. 8, n.3, p. 208-220, Fall 1999.

HESKETT, J. L;

SASSER, W. E.;

SCHLESINGER, L. A.

Putting the service-profit chain to work. Harvard Business Review, v. 72, n. 2, p. 165-174, Mar./Apr. 1994.

KELLEY, S. W.; HOFFMAN, K. D.;

DAVIS, M. A. A

typology of retail failures and recoveries. Journal of Retailing, v. 69 , n. 4, p. 429-452, Winter 1993.

LAPIDUS, R. S.;

SCHIBROWSKY, J. A.

Aggregate complaint analysis: a procedure for developing customer service satisfaction. Journal of Services Marketing, v. 8, n. 4, p. 50-60, 1994.

REICHHELD, F. F.

The loyalty effect. Boston: HBS Press, 1996.

REICHHELD, F. F.;

SASSER JR., W. E.

Zero defections: quality comes to services. Harvard Business Review, v. 68, n. 5, p.105-111, Sept./Oct. 1990.

SAMPSON, S. E.

Understanding service business. Brigham Young University, 1999. working paper.

STEWART, D.;

CHASE, R.

The impact of human error on delivering service quality. Production and Operations Management, v. 8, n.3, p. 240263, Fall 1999. 